\title{
Research progress on vehicle exhaust emission factor model and dispersion model
}

\author{
Lanyi Zhang ${ }^{a}$, Rongzu Qiu ${ }^{b}$ \\ College of Transportation and Civil Engineering, Fujian Agriculture and Forestry University, Fuzhou \\ 350002, China \\ azhang_lanyi@126.com, barz1010@yahoo.com.cn
}

\begin{abstract}
Keywords: vehicle exhaust; exhaust pollutant; emission factor; dispersion model
Abstract. Population, economy, resources and environment have received considerable concerns for human beings. A lot of resources are consumed due to demographics and growth prospects, while excessive utilization resources result in environment pollution problems which are intensified the conflict among environment and population, economy and environment on account of the development of industrial production and transportation. A large amount of fossil fuel are consumed by vehicles that exhaust gas emission more than 100 kinds of pollutants such as $\mathrm{CO} 2, \mathrm{CO}, \mathrm{NO} 2, \mathrm{SO} 2, \mathrm{PM} 2.5$ and so forth, these pollutants aggravate the greenhouse effect and air pollution. The paper reviewed vehicle exhaust emission factor and diffusion model at home and abroad, and summarized the problems existing in the research, and then the scientific outlook were carried on. Proposals were proposed that the research should take on the mountainous area highway which might stay away from the interference of industrial and residential areas. The review not only can help scholars build the high accuracy exhaust emission factor model and dispersion model, but also can provide vehicle pollution control of the foundation of scientific decision-making.
\end{abstract}

\section{Introduction}

Industrial development, population growth and the acceleration of urbanization brought by the rapid development of economy and science, on the one hand, has improved people's living standards, on the other hand, has brought unprecedented challenges to people' living environment, such as ecological environment, surface water environment, acoustic environment, air environment and so on, and air pollution is the most prominent environment issue. It is estimated that about 1.3 million people in the world died of outdoor air pollution each year ${ }^{[1]}$. Air pollution is resulted from pollutants of human activities and natural processes; if air pollutant concentration keeps increasing and surpasses the bearing capacity of the environment, it would lead to the collapse of natural purification system and bring baneful influences such as forest deterioration, acid rain, organism extinction, decrease of humans' living standards, degeneration of humans' health and endangerment of life and so on.

The birth of the first vehicle in 1886 changed people's trip mode and vehicle industry has embraced rapid development. Car ownership keeps increasing rapidly and the large quantities of fossil fuel they consume aggravates greenhouse effects and air pollution. $\mathrm{CO}_{2}$ emission from transportation has increased by $25 \%$ in the past 10 years and it is estimated to increase $30 \% \sim 50 \%$ until $2050^{[2]}$. In departments that consume energy in the world, the contribution rate of transportation industry to air pollutants reaches $23 \%$ and $\mathrm{CO}_{2}$ from motor vehicle exhaust emission takes up over $80 \%$ of that ${ }^{[3]}$. In the long run, the increase of $\mathrm{CO}_{2}$ emission will lead to the earth's surface warming, climate issues, ecological system issues, and energy security problems and so on, so attention must be paid to it.

Besides $\mathrm{CO}_{2}$, there are also over 100 types of other pollutants from vehicle exhaust, transforming the traditional "coal-smoke pollution" to "soot-tail gas mixed pollution" [4] In it, $\mathrm{CO}, \mathrm{NO}_{2}, \mathrm{SO}_{2}, \mathrm{PM}_{2.5}$ and other pollutants would endanger human body and crop growth severely. About 100ppm of CO would cause headache, fatigue and anoxia similar with carbon monoxide poisoning ${ }^{[5]}, \mathrm{NO}_{2}$ would stimulate respiratory system and cause chlorosis to trees and nitric acid rain and so on; about 1 5ppm of $\mathrm{SO}_{2}$ would cause palpitation, respiratory disturbance and even suffocation and inhibit crops' growth. $\mathrm{PM}_{2.5}$ would pass into the upper respiratory tract and deposite in bronchus and pulmonary alveoli, 
thereby causing asthma, trachitis, cardiovascular disease and so on ${ }^{[6]}$. In addition, the exhaust pollutant would also cause harms such as water pollution, soil contamination, sharp decline in biodiversity, destruction to architecture and so on.

The world has paid high attention to greenhouse effect and air pollution treatment. UK, US and other countries had issued Clean Air Act in the $20^{\text {th }}$ century for controlling and treating air pollution. The United Nations Environment and Development Convention had passed Framework Convention on Climate Change, Kyoto Protocol and so on in the $20^{\text {th }}$ century to cope with the increasingly severe global warming ${ }^{[7]}$. The $21^{\text {st }}$ contracting party convention of The United Nations Framework Convention on Climate Change convened in Paris in November 2015 encouraged all countries to participate in coping with climate change action in the way of autonomous contribution. China is a large developing country in the world, and air pollution and greenhouse effect brought by rapid development of economy is even significant. In June 2015, China proposed new goals of reducing $\mathrm{CO}_{2}$ emission of unit GDP by $60 \% \sim 65 \%$ until $2030^{[8]}$; also, China began to implement The People's Republic of China Atmospheric Pollution Prevention Law from January $1^{\text {st }} 2016$, aiming to control air pollution and greenhouse effect cooperatively, protect and improve the environment.

Air pollution is a livelihood issue. Environmental, ecological and human health problems resulted from vehicle exhaust manifests necessity of studying the pollutants and dispersal patterns of vehicle exhaust so as to reduce vehicle exhaust hazard and improve air quality. Vehicle exhaust is low-altitude emission. When vehicles run in residential area or business districts and other closed or gorge space, the air pollutant cannot dissipate in a short time. Therefore, air pollution resulted from vehicle exhaust in early stage mainly manifests in that pollutant concentration in the air rises significantly in a short period and causes influences on human body. Therefore, ever since the 1970s, researches at home and abroad mainly focus on cities, urban roads or industrial areas with large population or dense road network.

\section{Domestic and foreign research situations}

Research on the vehicle exhaust emission factor. Air pollution resulted from vehicles mainly depends on emission factor, road condition, transportation condition, air pollution bearing capacity and so on. Vehicle emission factor testing methods are bench test, tunnel test, remote sensing and vehicle-mounted test and so on. Bench test means using chassis dynamometer to simulate pollutant discharge factors when vehicles are running in all transport conditions. 22 light gasoline vehicles were chosen to conduct vehicle bench test, obtaining the vehicles' nitrous oxide and methane emission factor under NEDC condition(He et al., 2014) ${ }^{[9]}$. In laboratory conditions, bench test can design controlled test, which is convenient for obtaining vehicle emission factors, but it is easily to be restricted by laboratory conditions and there might be errors between the results and realities. Tunnel test is considered to be one of the ways that can minimize other pollutant sources and obtain real road traffic emission factors ${ }^{[10]}$. Relationship between pollutant concentration and traffic flow is set up by observing vehicle models and traffic flow that enter the tunnel so as to obtain the emission factors of different types of vehicles. Remote sensing test means setting up instruments by the road side and monitoring concentration of vehicle exhaust emission pollutants automatically and dynamically. Sensing data was combined to obtain underlying surface feature information in Shanghai, and they used infrared gas analyzer to monitor $\mathrm{CO}_{2}$ concentration belt transect on the ground(Pan et al., 2015) ${ }^{[11]}$. Remote sensing was used to study exhaust gas emission of vehicles, and the result showed that gasoline cars discharge more $\mathrm{CO}$ and HC but less NO than diesel vehicles(Jason et al., 2012) ${ }^{[12]}$. Vehicle-mounted test means obtaining the instantaneous conditions of the vehicle of the corresponding actual working conditions when running by emission analytical instrument, running state recorder and other relative equipment that are installed in the vehicle. Portable vehicle-mounted emission test system was used to test vehicle exhaust emissions and exhaust gas flow, and the result showed that exhaust gas emission of gasoline car was far below the emission standard, while NOx in diesel vehicle emission pollutants often exceeded standards in actual driving states(Marina et al., 2013) ${ }^{[13]}$. 
Besides the above test methods to obtain vehicle emission factors, developed countries as Europe and America were dedicated to establishing emission factor model to solve micro, mid and micro emission factors in the 1970s. For example, MOBILE series model developed by USA EPA, EMFAC and MVEI Model developed by American California Air Resource Bureau, COPERT Model developed EU Environment Agency and so on. These models have considered the vehicle's durable years, new vehicle emission factor, and actual service life, running speed, temperature, deterioration factor, detection / maintenance system and automotive oil plant characteristics and so on. Hyung-Wook Choi utilized MOBILE6 emission factor model to estimate instant emission pollutants of vehicles whose speed was no more than 65 miles/ hour and he used portable emission test system to develop correction factor of high speed and constant speed of cars. However, potential errors of the model is that it cannot explain that when cars are running on expressways in middle speed, the emissions are $25 \%$ higher than when they are running in high speed ${ }^{[14]}$. Remote sensing technology was used to calculate $\mathrm{CO}, \mathrm{HC}$, NO road exhaust pollutant discharge amount in these several years in Denver, and then he compared the measured values with predicted values of MOBILE6(Pokharel et al., 2002) ${ }^{[15]}$. Principles of emission factor model are constructing indicators influencing vehicle emission and obtaining vehicle emission factors on the basis of modifying and improving; the obtained values can reflect the actual emission situation of the vehicles, so it is recognized by experts and widely applied in researches.

Currently, there is no relative emission factor mode established according to Chinese roads and actual conditions of cars and existing researches are applied after referring to the existing models of developed countries. Tsinghua University was the first ones to use MOBILE5 Model to determine HC, CO, NOx emission factors in 1998 and modified new vehicles' emission factors and deterioration factors(He et al., 1998) ${ }^{[16]}$. Later, Chinese experts cited MOBILE, COPERT, IVE and other models to calculate vehicle emission factors in Beijing, Guangzhou, Hangzhou and other places one after another. MOBILE, EMFAC, CMEM, IVE, COPERT and other models were concluded and compared, and were pointed out that when using models to calculate pollutant emission factors, model adaptation should be taken into consideration(Ma et al., 2008) ${ }^{[17]}$. According to real traffic flow information, ArcGIS was adopted to analyze spatial distribution of pollutant factor data, vehicle exhaust volume and pollutant discharge with spatial and temporal distribution characteristic. The result showed that there was positive correlation between pollutant discharge intensity and traffic volume(Fan et al., $2015)^{[18]}$.

Research on the vehicle exhaust pollutant dispersal model. Pollutant dispersal pattern calculation can be divided into box mode, Gaussian mode and experience mode according to different physical model hypotheses. According to different roads and constructions at both sides, different pollutant dispersal patterns would be adopted. Aiming at different pollutant dispersal patterns, different dispersal modes are adopted.

Representative modes of box mode tail gas pollutant dispersal pattern is Chicago formula and street canyon smoke plum mode and so on, which is mainly used in streets, canyons and closed areas. Gaussian mode takes into consideration of vehicle running turbulence effect and meteorological conditions such as wind direction, wind speed, temperature and so on, and it is mainly used in vehicle pollutant simulation of broad and flat roads. Gaussian mode in early stages is HIWAY and HIWAY-2 developed by Environmental Protection Agency and it can be used in simulating vehicle exhaust pollutant dispersion on two or more roads at different times and it can suit simulation researches of large scales; CALINE mode conducts simulated pollutant diffusion by inputting pollution sources, meteorological conditions, coordinates and other parameters in California. Experience mode is mainly used in elevated roads and fracture surfaces. Representative mode is JEA formula developed by Japanese Province of Environment, but it lacks theoretical support, so it is not suitable for pollutant dispersal simulation of large scales ${ }^{[19]}$.

Pollutant dispersal researches of China in current stages mainly use relatively mature box mode and Gaussian mode in developed countries, and Gaussian mode is used most widely. GIS was combined with two Gaussian modes of traditional HIWAY-2 and CALINE-4, and studied vehicle 
exhaust pollutant nitric oxide and PM 10 dispersal pattern of Xiamen. The conclusion is that NOx and $\mathrm{PM}_{10}$ mass concentration would decrease with the increase of wind speed and would increase with the increase of traffic flow. They used GIS space superposition and found that mass concentration in part of Xiamen's pollutants is over-proof(Shi et al., 2010) ${ }^{[20]}$ and they conducted further researches on $\mathrm{SO}_{2}$ and $\mathrm{PM}_{2.5}$ (Shi et al., 2014) ${ }^{[21]}$.

In recent years, scholars have been dedicated to exploring more accurate vehicle emission pollutant dispersal mode, algorithms and software researches. Half-empirical formula city street model was proposed which used emission speed of pollutant, width of street and canyon, scope of pollutant diffusion and background concentration and simple math mode to calculate air pollutant concentration in the street and canyon(Venegas et al., 2014) ${ }^{[22]}$. A statistics mode based on spatially varying coefficient model was proposed and was conducted assessment on air quality through maps and proposed mitigation measures so as to improve influences of $\mathrm{PM}_{10}$ on health(N.A.S. et al., 2015) ${ }^{[23]}$. Geographical model based on tracks and artificial neural network of wavelet transform was used to improve the forecast accuracy of $\mathrm{PM}_{2.5}$ (Feng et al., 2015) ${ }^{[24]}$. Gaussian dispersal modelwas adopted to forecast and assess motor traffic pollutant $\mathrm{CO}$ and $\mathrm{PM}_{2.5}$ within the fifth ring of Beijing. The result showed that the forecast result conformed to the trend of actual values in time changes basically. Results of morning peaks were quite accurate, while evening peaks were quite advanced(Lu et al., $2015)^{[25]}$.

\section{Analysis on existing problems}

problem of Pollution traceability. The current measurement of emission factors are inclined to refer to mature models in developed countries for modification and improvement, and research objects are usually cities or city roads. However, measurement of city exhaust pollutant may be disturbed by industrial pollutant sources and residential living fuel burning surface sources and so on and the data might be problematic of various pollution sources, so it has become a problem about how to calculate exhaust pollutant.

problem of direct reference model. When calculating vehicle exhaust emission factors and diffusion models, most scholars just rely on foreign mature models for calculation of emission factors or research of diffusion models directly. However, mature models of calculating exhaust emission factors require numerous parameters, which are not easy to be obtained in China. Therefore, default parameters have to be used and there are some differences between the obtained emission factors and vehicle emission level in China. Besides, when studying emission factors, part of the researches lack enough field test and data analysis and the chosen emission factors cannot reflect pollution of real roads comprehensively. In addition, when studying diffusion models of exhaust pollutant, Chinese transportation, city structure and transportation rules differ from those in foreign countries. Therefore, there might be some errors between the obtained simulation and the real diffusion patterns when foreign Gaussian mode and Box mode and so on are applied in road pollutant diffusion simulation under Chinese national conditions directly.

\section{Conclusions}

From the existing literatures, we can see that most of the researches about exhaust pollutant emission factors and diffusion models concentrate on city roads, industrial areas and so on, and environmental, ecological and human health problems resulted from canyon space of closed city roads, vehicle low-altitude emission pollutants that are difficult to dissipate in short time, significant rise of pollutant concentration and exhaust pollutants show the necessity of researches. The current researches lack researches on mountain roads. However, mountain roads have not caught due attention because of their unique advantages.

First of all, air pollutant discharged by various pollution sources not only cause urban air pollution, but also cause air pollution in mountainous areas by atmospheric transport and dispersion. Although trees are planted on the both sides of mountain area highways and trees possess the functions of 
absorbing, blocking and filtering pollutant of vehicle exhaust, the density of air pollutant exceeds the purification capacity and the harm shall not be underestimated.

Second of all, economic exchange, urban integration acceleration and convenient travel may be realized to construct mountain highways. For purpose of mountain highways opening to traffic, it is demanded to dig tunnels and build roads on the mountainous forest land. The forest ecological environment is damaged artificially. The influence of exhaust pollutants discharged by vehicle flow on animals, plants as well as soil on the both sides of the highways is not easily perceived and predicted in the short term. However, in recent years, reports regarding reduction of biodiversity caused by endangered wild animals, reduction of forest coverage, desertification caused by serious water and soil loss, ecological function decline of forests influencing stand growth of forests, acid rain accelerating acidification process of forest soil are common. All these problems are inseparable from air pollution.

Then, mountain highways are far from industrial areas and residential areas, which may eliminate other interference and is in favor of the analyzing research on emission factors of vehicle exhaust pollutants. To conduct research on vehicle exhaust pollutants on the condition of mountain highways, the emission factors of vehicles shall reflect the emission status of vehicles contributing to reveal emission characteristics of vehicles on mountain highways and the distribution law of exhaust pollutants in the air, which may provide reference values for research on pollutant emission of vehicle exhaust on the condition of urban highways.

Therefore, a vehicle exhaust pollutant emission factor model suitable to China needs to be studied. Also, according to Chinese road characteristics, the diffusion rules of exhaust pollutant need to be studied on the basis of emission factors so as to obtain vehicle exhaust pollutant emission and diffusion model suitable to China, which is conductive to managing and controlling exhaust pollutant and protecting the environment.

\section{Acknowledgements}

This work was financially supported by Science and technology program of Fujian Municipal Education Commission (JB14005), Youth project of Fujian social sciences planning project (FJ2015C148) and Key projects of high level university construction by Fujian Agriculture and Forestry University (113-612014018). The corresponding author of this paper is Rongzu Qiu.

\section{References}

[1] World Health Organization Fact sheet N313: Air Quality and Health[EB/OL]. WHO, [2011-09]. http://www.who.int/mediacentre/factsheets/fs313/en/index.html.

[2] Yang, Q., Zhu, R., Zhao, X., 2014. Calculation decoupling analysis and scenario prediction of carbon emissions of transportation in China. Journal of Chang'an University(Natural Science Edition). 34(5), 77-83.

[3] Jin, D., Wei, J., Wu, S., Sun, H.,2015. The analysis of new energy automotive industry in China. China Science and Technology Expo. 34, 307.

[4] Zhu, C., Zhou, Y., He, W.,2001. Automobile environmental protection. Zhejiang university press.

[5] Li, H., 2015. The origins of vehicles exhaust damage and prevention measures. Environmental Protection \& Circular Economy. (6), 54-56.

[6] Hu, J., Xu, H., Li, Q., Tang, Z., Yu, Y., Liu, Y., Sun, J., Fu, Y., Tu, C., 2015. The research progress on impact and related mechanism of fine particulate matter PM2.5 on diseases of the body system. Journal of Clinical Pulmonary Medicine. (5), 926-928.

[7] Xia, K., 2015. The United Nations framework convention on climate change (unfccc) 23 years. World Environment. (4), 58-67.

[8] The editorial of Energy of China, 2015. Enhanced action on climate change-- Submission climate change independent contribution in China. Energy of China. (7), 1. 
[9] He, L., Song, J., Hu, J., Xie S., Zu L., 2014. An Investigation of the $\mathrm{CH}_{4}$ and $\mathrm{N}_{2} \mathrm{O}$ Emissiion Factors of Light-duty Gasoline Vehicles. Environmental Science, (12), 4489-4494.

[10] Célia A. Alvesa, Joana Gomesa, Teresa Nunesa, Márcio Duartea, Ana Calvob;Danilo Custódioa, Casimiro Pioa, Angeliki Karanasiouc, Xavier Querolc, 2015. Size-segregated particulate matter and gaseous emissions from motor vehicles in a road tunnel. Atmospheric Research. 153, 134-144.

[11] Pan, C., Zhu, X., Jia, W., Yang, F., Liu, M., Xiang, W., 2015. Near surface CO2 concentration and its quantitative relationship with character of underlying surface in Shanghai City, China. Chinese Journal of Applied Ecology, (7), 2123-2130.

[12] Jason Laua, W.T. Hunga, C.S. Cheungb, 2012. Observation of increases in emission from modern vehicles over time in Hong Kong using remote sensing. Environmental Pollution. 163, 14-23.

[13] Kousoulidou, Marina;Fontaras, Georgios;Ntziachristos, Leonidas, Bonnel, Pierre, Samaras, Zissis, Dilara, Panagiota, 2013. Use of portable emissions measurement system (PEMS) for the development and validation of passenger car emission factors. Atmospheric Environment. 64, 329-338.

[14] Hyung-WookChoi, H. Christopher Frey, 2009. Light duty gasoline vehicle emission factors at high transient and constant speeds for short road segments. Transportation Research Part D. 14(8), 610-614.

[15] Pokharel, Sajal S., Bishop, Gary A.1, Stedman, Donald H, 2002. An on-road motor vehicle emissions inventory for Denver: an efficient alternative to modeling. Atmospheric Environment. 36(33), 5177-5184.

[16] He, D., Hao, J., He, K., Fu, L., 1998. Vehicle Emission Factors Determination Using Model Calculation. Chinese Journal of Environmental Science. (3), 7-11.

[17] Ma, Y., Alexis.K.H.LAU, Peter.K.K.LOUIE, Li, T., Luan, S.,2008. Application of Vehicular Emission Models and Comparison of Their Adaptability. Acta Scientiarum Naturalium Universitatis Pekinensis. (2), 308-316.

[18] Fan SB, Tian LD, Zhang DX, Qu S, 2015. Emission Characteristics of Vehicle Exhaust in Beijing Based on Actual Traffic Flow Information. Huan Jing Ke Xue. 36(8), 2750-2757.

[19] Liu, K., Yuan, Y., Luo, C., Sun, D.,2009. Summary of vehicle emission and diffusion models in typical urban streets. The Administration and Technique of Environmental Monitoring. 21(6), 8-14.

[20] Shi, Y., Wang, J., Cao, C., Huang, Z., Li, Q., 2010. Diffusion Simulation of Automobile Emission in Urban Area of Xiamen city based on GIS. Journal of Jimei University(Natural Science), (6), 466-470.

[21] Shi, Y., Wang, J., Zhang, Z., 2014. Analysis on spatial distribution of air pollution and its spatial correlation with influencing factors in Xiamen City. Chinese Journal of Environmental Engineering, (12), 5406-5412.

[22] Venegas, Laura E, 2014. A simple model for calculating air pollution within street canyons. Atmospheric Environment. 87, 77-86.

[23] N.A.S. Hamm, A.O. Finley, M. Schaapc, A. Steina, 2015. A spatially varying coefficient model for mapping PM10 air quality at the European scale. Atmospheric Environment. 102, 393-405.

[24] Feng, X., Li, Q., Zhu, Y., Hou, J., Jin, L., Wang, J.,2015. Artificial neural networks forecasting of PM2.5 pollution using air mass trajectory based geographic model and wavelet transformation. Atmospheric Environment. 107, 118-128.

[25] Lu, N., Yao, E., Pan, L., Pan Z., 2015. Sensitivity Analyses of the Traffic-related Air Pollution in Beijing Based on Gaussian Dispersion Models. Road Traffic \& Safety, (2), 55-60. 